\section{AB1398-HPR THE EFFECTS OF KINESIOPHOBIA ON PAIN, FATIGUE SEVERITY, FUNCTIONAL EXERCISE CAPACITY, FUNCTIONAL STATUS AND QUALITY OF LIFE IN FIBROMYALGIA}

C Gülșen ${ }^{1}$, A. GÜÇLÜ GÜNDÜZZ1 , F. SÖKE ${ }^{1}$, K. ÇEKIM ${ }^{1}$, Y. AYDIN ${ }^{1}$, D. AKÇALI ${ }^{2}$

${ }^{1}$ Faculty of Health Sciences, Department of Physiotherapy and Rehabilitation;

${ }^{2}$ Pain Clinic, School of Medicine, Gazi University, Ankara, Turkey

Background: Kinesiophobia play an important role in the development of chronic pain in Fibromyalgia (FM) patients. This condition lead to increase clinical symptoms and reduce quality of life.

Objectives: The aim of the study is to examine the effects of kinesiophobia on pain, fatigue, functional exercise capacity,functional status and quality of life in FM patients.

Methods: Twenty-one FM patients were evaluated. We used Tampa Scale of Kinesiophobia (TSK) for perception kinesiophobia, Visual Analogue Scale (VAS) for pain intensity, Fatigue Severity Scale (FSS) for fatigue, six-minute walk test (6MWT) for functional capacity, Fibromyalgia Impact Questionnaire (FIQ) for the functional status, and Short-Form Health Survey (SF-36) for quality of life.

Results: The results of this study, there was a strong correlation between TSK and VAS, FSS, physical and mental components of SF-36 ( $r=0.754$, $r=0.762, r=0.780$, and $r=0.843$, respectively; $p<0.05$ ). There was a moderate correlation between TSK and FIQ and 6MWT $(r=0.695, \quad r=0.510$, respectively; $\mathrm{p}<0.05$ ).

Conclusions: The results of the present study indicate that kinesiphobia can adversely affect pain, fatigue, functional status and functional exercise capacity, which is result in impaired quality of life in FM. Further, it demonstrates kinesiophobia can be a clinically appropriate assessment to evaluate patients and to determine the effectiveness of treatments in FM. Disclosure of Interest: None declared

DOI: 10.1136/annrheumdis-2018-eular.5323

\section{AB1399-HPR CONCURRENT VALIDITY AND STABILITY OF SUBGROUP ASSIGNMENT TO THREE LEVELS OF PAIN CONDITION SEVERITY IN PATIENTS WITH MUSCULOSKELETAL PAIN}

C Emilson $^{1}$, I. Demmelmaier ${ }^{1}$, S. Bergman ${ }^{2}$, S. Pettersson ${ }^{3}$, P. Åsenlöf ${ }^{1}$. ${ }^{1}$ Department of Neuroscience, Uppsala University, Uppsala; ${ }^{2}$ Department of Public Health, and Community Medicine, Institute of Medicine, The Sahlgrenska Academy, University of Gothenburg, Gothenburg; ${ }^{3}$ Department of Neurobiology, Care Scienceand Society, Division of Physiotherapy, Karolinska Institutet, Stockholm, Sweden

Background: Pain screening instruments have been used to identify risk factors for poor prognosis and are recommended for the stratification of treatment for musculoskeletal pain.

Objectives: The aim of this study was to investigate the concurrent validity of subgroup assignment based on the Örebro Musculoskeletal Pain Screening Questionnaire compared with reference instruments: The Pain Disability Index, the Tampa Scale for Kinesiophobia, and the Pain Catastrophizing Scale. A secondary aim was to investigate the stability of the subgroup assignment over a defined period of time.

Methods: Participants $(n=40)$ aged 18-65 years were recruited from five primary health care centres in Sweden. Data were collected using selfreported questionnaires. The subgroups based on the Örebro Musculoskeletal Pain Screening Questionnaire were pre-defined to low, moderate or high pain condition severity. The reference instrument data were dichotomized into low or high level based on previously used cut-off scores. Concurrent validity was analysed with Fisher's exact test. Stability was calculated using quadratic-weighted kappa analysis.

Results: The results indicated acceptable psychometric properties of the subgroup assignment based on the Örebro Musculoskeletal Pain Screening Questionnaire regarding concurrent validity, and the stability $\left(K_{\mathrm{w}}: 0.51\right.$, $95 \% \mathrm{Cl}: 0.22-0.81)$ over two to three weeks. To further increase validity, it is suggested that subgroup assignment is complemented with other measures assessing e.g. pain catastrophizing.

Conclusions: In conclusion, assignment to subgroups with low, moderate and high levels of pain condition severity based on the Örebro Musculoskeletal Pain Screening Questionnaire, could be used as a valid basis for stratified treatment for patients with musculoskeletal pain.

\section{REFERENCES:}

[1] Linton SJ, Boersma K. Early identification of patients at risk of developing a persistent back problem: the predictive validity of the Orebro Musculoskeletal Pain Questionnaire. The Clinical journal of pain. 2003;19(2):80-86.
[2] Hill JC, Dunn KM, Main CJ, Hay EM. Subgrouping low back pain: a comparison of the STarT Back Tool with the Orebro Musculoskeletal Pain Screening Questionnaire. European journal of pain. 2010;14(1):83-89.

[3] Soer R, Koke AJ, Vroomen PC, et al. Extensive validation of the pain disability index in 3 groups of patients with musculoskeletal pain. Spine. 2013;38(9):E562-568.

[4] Lundberg MKE, Styf J, Carlsson SG. A psychometric evaluation of the Tampa Scale for Kinesiophobia - from a physiotherapeutic perspective. Physiotherapy theory and practice. 2004;20(2):121-133.

[5] Sullivan MJL, Bishop SR, Pivik J. The Pain Catastrophizing Scale: Development and validation. Psychological Assessment. 1995;7(4):524-532.

Acknowledgements: The study received financial support from the Swedish Rheumatism Association, Uppsala County Council, and Caring Sciences Funding at the Faculty of Medicine, Uppsala University.

Disclosure of Interest: None declared

DOI: 10.1136/annrheumdis-2018-eular.7207

\section{AB1400-HPR MUSCLE QUALITY INDEX IN OBESE SUBJECTS WITH HIP OSTEOARTHRITIS}

D.A Jerez ${ }^{1}$, R. Machado ${ }^{2}$, E. Cerda ${ }^{3} .{ }^{1}$ Ciencias de la Rehabilitacion, Universidad Andres Bello, Santiago, Chile; ${ }^{2}$ Facultad de Ciencias del Deporte, Universidad de Granada, Granada, Spain; ${ }^{3}$ Clencias de la salud, Universidad Catolica de Chile, Santiago, Chile

Background: Obese older adults with hip osteoarthritis suffer a progressive loss of neuromuscular function affecting their activities of daily living Objectives: The objective of this study is to determine the behaviour of the muscular quality index in obese subjects with osteoarthritis and to compare the manifestations of strength and anthropometric variables with control subjects.

Methods: Thirty-two subjects (4 men and 28 women, $66.2 \pm 5.2$ years of age, $159.2 \pm 7.5 \mathrm{~cm}, 71.5 \pm 11.7 \mathrm{~kg}$ ) were evaluated. 14 subjects suffered osteoarthritis. Muscle circumference, limb length, body mass and sit and stand test were evaluated, in addition to the maximal voluntary isometric contraction in hip flexion and extension movements.

Results: The osteoarthritis group presented obesity $(p=0.037)$. The muscle quality index of the osteoarthritis group correlated with the weight $\left(p=0.776^{* *}\right)$, with maximum peak strength in flexion $\left(p=0.552^{*}\right)$ and average maximal strength $\left(p=0.574^{\star}\right)$. In the control group the muscle quality index correlated with: weight $\left(\mathrm{p}=0.689^{* *}\right)$, muscle circumference $\left(p=0.571^{\star}\right)$, maximum peak strength in extension $\left(p=0.534^{\star}\right)$, average peak strength in extension $\left(p=0,523^{*}\right)$, average maximal strength in extension $\left(p=0.509^{*}\right)$ and maximum impulse in extension $\left(p=0.508^{*}\right)$.

Conclusions: The muscle quality index is a useful tool to measure muscle quality in the healthy population, but is not clear enough for obese subjects with osteoarthritis, so it is necessary to perform future studies to determine their behaviour.

\section{REFERENCES:}

[1] Fragala MS, Kenny AM, Kuchel GA. Muscle quality in aging: a multidimensional approach to muscle functioning with applications for treatment. Sports medicine (Auckland, NZ). 2015;45(5):641-58. Epub 2015/02/07. doi: 10.1007/s40279-015-0305-z. PubMed PMID: 25655372.

[2] Fragala MS, Fukuda DH, Stout JR, Townsend JR, Emerson NS, Boone $\mathrm{CH}$, et al. Muscle quality index improves with resistance exercise training in older adults. Experimental gerontology. 2014;53:1-6. Epub 2014/02/11. doi: 10.1016/j.exger.2014.01.027. PubMed PMID: 24508922.

[3] Barbat-Artigas S, Rolland Y, Zamboni M, Aubertin-Leheudre M. How to assess functional status: a new muscle quality index. The journal of nutrition, health \& aging. 2012;16(1):67-77. Epub 2012/01/13. PubMed PMID: 22238004.

[4] Takai $Y$, Ohta M, Akagi R, Kanehisa H, Kawakami $Y$, Fukunaga T. Sit-tostand test to evaluate knee extensor muscle size and strength in the elderly: a novel approach. J Physiol Anthropol. 2009;28(3):123-8. PubMed PMID: 19483373

[5] van Lummel RC, Walgaard S, Maier AB, Ainsworth E, Beek PJ, van Dieën JH. The Instrumented Sit-to-Stand Test (iSTS) Has Greater Clinical Relevance than the Manually Recorded Sit-to-Stand Test in Older Adults. PLoS ONE. 2016;11(7):e0157968. doi: 10.1371/journal.pone.0157968. PubMed PMID: PMC4938439.

Disclosure of Interest: None declared

DOI: 10.1136/annrheumdis-2018-eular.4586 